(C) This manuscript version is made available under the CC-BY-NC-ND 4.0 license https://creativecommons.org/licenses/by-nc-nd/4.0/

\title{
Nonsuicidal Self-Injury among Youth
}

Following the 2007 definitional consensus of nonsuicidal self-injury (NSSI), there have been significant advances in our understanding of the behavior, particularly among children, adolescents, and young adults. ${ }^{1}$ Given the tremendous growth of the field, in 2013 the American Psychiatric Association incorporated NSSI into their diagnostic manual as a disorder warranting further research. ${ }^{2}$ NSSI is defined as the deliberate immediate destruction of one's own body tissue (eg, self-cutting, bruising, burning) in the absence of conscious suicidal intent. This definition excludes socially accepted practices such as tattooing and body piercing. ${ }_{-}$ Stereotypic and repetitive self-injurious behavior by youth with developmental disabilities and neuropsychiatric disorders as well as major forms of NSSI (eg, bone breaking, amputation) are subsumed under the broad umbrella of NSSI behaviors ${ }^{3}$; however, the current review focuses on NSSI that occurs in typically developing youth, which is consistent with current conceptualizations in the field. $\frac{3-5}{-5}$

NSSI represents a paramount health issue for youth and young adults, with as many as 1 in 5 youth reporting engagement in the behavior. $\stackrel{3,6,7}{ }$ Moreover, NSSI has been consistently shown to be associated with numerous psychiatric difficulties. $\underline{4-6,8}$ Of most concern is recent research indicating that NSSI confers risk for future suicide attempts. ${ }^{9-12}$ Furthermore, health professionals have reported increasing numbers of patients presenting with NSSI across a number of health setting contexts. $\stackrel{13,14}{ }$ Collectively, these reports suggest that pediatricians, primary care physicians, and other medical professionals who work with adolescents will likely encounter youth who self-injure. Hence, it is important that physicians and other medical professionals be equipped with up-to-date NSSI knowledge and guidelines as these encounters often represent an initial point of contact for youth experiencing health and mental health 
(C) This manuscript version is made available under the CC-BY-NC-ND 4.0 license

https://creativecommons.org/licenses/by-nc-nd/4.0/

issues. $\frac{14,15}{}$

Taliaferro et al examined how prepared pediatricians, primary care physicians, family

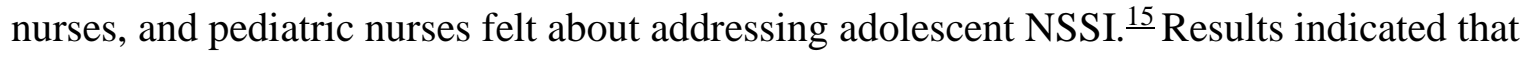

almost one-half felt underprepared; over $70 \%$ wanted more information and training in this area.

Others have also suggested that medical professionals may not be prepared to address NSSI and may even hold NSSI misconceptions.., 16 Presently, however, there are a limited number of articles providing reviews and recommendations for medical professionals who work with those who self-injure. ${ }^{7,14}$ Although useful, none of these reviews focus primarily on NSSI in children and adolescents. $\frac{6,9,14}{}$ Because of the rapidly evolving state of the field, the information provided in previous re- views is no longer completely representative of current knowledge. Thus, the present review summarizes the most recent findings concerning NSSI and corresponding guidelines for physicians.

\section{Epidemiology}

NSSI onset occurs throughout the lifespan, with peak onset periods during early (14-15 years of age) and late (17-18 years of age) adolescence. ${ }^{17-19}$ However, approximately one-fifth of those with a history of NSSI, report that they began self- injuring before age $12 .{ }^{20,21}$ Research indicates that the life- time prevalence (ie, whether individuals have ever self- injured in their lifetime) for preadolescence NSSI is estimated to be approximately $7.60 \% .{ }^{21}$ As this is a newer area of study, the past year prevalence of NSSI among preadolescent youth is not yet known. Rates between males and females during preadolescence appear to be similar. ${ }^{21}$ Amongst adolescents, NSSI rates are typically higher than in preadolescence, with lifetime prevalence ranging from $14 \%-24 \%^{3,6,22}$; the past year prevalence of NSSI among adolescents is about $6 \%-7 \% .{ }^{6}$ In contrast to findings among pre- adolescents, most studies report a higher 
(C) This manuscript version is made available under the CC-BY-NC-ND 4.0 license

https://creativecommons.org/licenses/by-nc-nd/4.0/

prevalence of NSSI for adolescent females than males, ${ }^{18,23}$ although some studies report no sex differences in this age group. ${ }^{23,24}$ In samples of young adults, lifetime and past year reports are similar to those reported among adolescents, ${ }^{19,25,26}$ with comparable prevalence rates for males and females. ${ }^{19,25,26}$

\section{NSSI Presentation}

The most commonly endorsed methods of NSSI tend to include scratching, cutting, bruising, head banging, and burning. ${ }^{6,18,23,24,26,27}$ Although some youth report a single method, many use multiple methods..$^{6,19,23,24,26,27}$ Further- more, males are more likely to report bruising, head banging, and burning, whereas females are more likely to report cut- ting and scratching. ${ }^{19,27}$

Current evidence suggests NSSI will most commonly co- occur with a number of core psychological difficulties, including but not limited to emotion regulation difficulties, inattention, impulsivity, negative cognitive style (eg, pessimism), self-hatred, and possible dissociation or problematic body image. ${ }^{28-35}$ In addition, certain psychiatric disorders have been found to co-occur with NSSI such as eating disorders (with higher risk among those diagnosed with bulimia), mood disorders (eg, depression, dysthymia), anxiety disorders (eg, post-traumatic stress disorder), and substance abuse. ${ }^{11,20,35-41}$ Not surprisingly, as NSSI represents one of the diagnostic symptoms of borderline personality disorder (BPD), many individuals with BPD engage in NSSI. However, in community samples of youth who self-injure the majority do not meet diagnostic criteria for BPD. ${ }^{39}$ Additional risk factors for NSSI include family dysfunction (eg, attachment difficulties, parental criticism, loss) and childhood abuse. ${ }^{26,41,42}$ Similar to the relation between NSSI and BPD, although many of those who report these factors engage in NSSI, in community samples of youth who self-injure many do not report family dysfunction or abuse. Collectively, these recent findings highlight the need to be alert to the different 
(C) This manuscript version is made available under the CC-BY-NC-ND 4.0 license

https://creativecommons.org/licenses/by-nc-nd/4.0/

presentations of NSSI among male and female patients and the possibility of co-occurring psychiatric difficulties.

Why Youth Self-Injure

NSSI represents a complex concomitant of psychological, social, and biological factors. Hence, understanding why adolescents engage in NSSI merits consideration of intrapersonal and social functions as well as the biological processes believed to underlie NSSI enactment.

\section{NSSI Functions}

Intrapersonal. Although commonly viewed as an attention-seeking and manipulative behavior, NSSI is seldom used to garner attention or manipulate others. Rather, a substantial body of literature indicates that there are various motives for NSSI, which can be conceptualized as intrapersonal or social in nature. The most commonly reported reason for NSSI is to regulate unwanted affective experiences such as distress, anxiety, and frustration that are perceived to be intolerable. ${ }^{31,43-47}$ Although a large number of youth who self-injure report affect regulation reasons for their NSSI, other reasons are reported. These include but are not limited to punishing oneself, reducing feelings of numbness or dissociation, to generate a feeling when feeling emotionally empty, and averting suicidal impulses or urges. ${ }^{31,43,46,47}$

Social. Reported less frequently are social reasons for NSSI, which often signal difficulty with interpersonal problem solving. For example, some youth who self-injure may do so in order to communicate their distress to others. ${ }^{31,43,46,47}$ To this end, researchers have demonstrated that relative to youth with no NSSI history, those who have self-injured have more difficult effectively resolving interpersonal situations and are less generative when developing resolutions. ${ }^{48}$ Other social reasons may involve self-injuring to belong to a group - often other youth who self-injure. Interestingly, social rea- sons may contribute to NSSI initiation for some youth, with intrapersonal reasons contributing to NSSI repetition. ${ }^{25,49}$ Other reported initial reasons for 
(C) This manuscript version is made available under the CC-BY-NC-ND 4.0 license

https://creativecommons.org/licenses/by-nc-nd/4.0/

NSSI include "accidental" discovery of the behavior or engaging in NSSI as an impulsive response to emotional turmoil. $19,25,50$

\section{Biology of NSSI}

A number of neurobiological processes have been implicated in NSSI. Of note are endogenous opioids and serotonin. Re- searchers have found that adolescents who self-injure have lower opioid levels than those who have not self-injured ${ }^{51,52}$ In particular, adolescents with an NSSI history have been found to have lower levels of b-endorphin and metenkephalin relative to those with no NSSI history. ${ }^{52,53}$ Thus, it may be that when youth self-injure, they elevate their levels of endogenous opioids, which would align with research indicating that youth may selfinjure in order to generate a feeling or to relieve feelings of numbness and dissociation. ${ }^{31}$ Lower levels of serotonin may also play a role in NSSI, specifically in terms of its initiation and repetition. ${ }^{53-55}$ Indeed, young people who self-injure have been found to have lower levels of peripheral serotonin than those who do not self- injure. ${ }^{54,55}$ Related to this, researchers have examined peripheral serotonin and its relation to mother-child interaction patterns in a sample of adolescents with a NSSI history. Here, a significant interaction between peripheral serotonin levels, negativity, and conflict between mothers and their adolescents was found. Interestingly, this interaction explained over $60 \%$ of the variance in youth NSSI. Thus, biological mechanisms and environment may interact to contribute to NSSI among adolescents. ${ }^{55}$

In addition, researchers have found that youth who self- injure have different levels of physiological arousal when responding to images of cutting. Specifically, in 1 study examining how age-matched female youth responded to NSSI imagery, those with a NSSI history reported that images of cutting were more emotionally arousing; this was corroborated by differences in neural patterns identified using functional magnetic resonance imaging. ${ }^{56}$ Other biological 
(C) This manuscript version is made available under the CC-BY-NC-ND 4.0 license

https://creativecommons.org/licenses/by-nc-nd/4.0/

mechanisms implicated in the understanding of NSSI include the dopaminergic system and the hypothalamic-pituitary- adrenal stress system; research, however, is scant in these areas. ${ }^{51,53}$ Despite these findings, implications regarding medication to manage NSSI remain tentative at best. ${ }^{57}$ The role of biological mechanisms represents a very recent area of study necessitating further research attention.

\section{NSSI and Suicide}

The relation between NSSI and suicide has received increasing empirical and clinical interest in the past several years. ${ }^{9-12,58,59}$ Accordingly, our understanding of this complex association has evolved substantially. Although suicide attempts and NSSI are distinct on the basis of their underlying motivations, they are often interconnected. ${ }^{60}$ Examples of underlying motivations for suicide attempts include to end one's life and to end one's level of psychological pain, whereas NSSI motivations refer more typically to affect regulation, self-punishment, and cessation of dissociative experiences. ${ }^{61}$ Despite these divergent motivations, a substantial proportion of youth who self-injure also report a past suicide attempt ${ }^{11,22}$; moreover, prospective studies indi- cate that NSSI serves as an important risk factor for later suicide attempts. ${ }^{61}$ One study suggested that NSSI confers a seven-fold increase in risk for suicide attempt. ${ }^{61}$

Factors such as frequency and method of NSSI are also important to consider when delineating NSSI and suicidality. Suicidal behaviors are usually characterized as being lower frequency and having a higher level of perceived lethality than NSSI. Although NSSI and suicide attempts can be distinguished on the basis of a number of factors, recent research suggests that specific aspects of the NSSI may contribute to suicide risk. For example, researchers have found that a longer-standing history of NSSI, using more NSSI methods, and reporting no physical pain at the time of injury may exacerbate suicide risk. ${ }^{11}$ Others have found that when controlling for 
(C) This manuscript version is made available under the CC-BY-NC-ND 4.0 license

https://creativecommons.org/licenses/by-nc-nd/4.0/

shared risk factors of NSSI and sui- cide, NSSI remains as a significant predictor of suicide attempts. ${ }^{9,12}$ Indeed, even after controlling for symptoms of depression, BPD, and impulsivity, NSSI still has a significant association with attempted suicide. ${ }^{10}$

In summary, only recently has research begun to highlight the significance of NSSI as a unique and robust risk factor for suicidal behavior. ${ }^{9-12,58,61}$ This newly emerged evidence has important implications for practice. Specifically, even though there are a number of notable differences between NSSI and suicide, all youth who present with NSSI should be assessed for suicide risk.

\section{Recommendations for Physicians}

\section{Screening}

In the event that a patient presents with 1 or more of the abovementioned risk factors, an initial assessment for possible NSSI is warranted. If the physician has reason to believe the patient may be engaging in NSSI, it is recommended that the physician poses a series of questions probing the youth's overall stress as well as use of adaptive and maladaptive coping strategies (Table). This approach has been found by clinicians and physicians to facilitate the identification of NSSI without drawing undue attention to the behavior. ${ }^{5,15}$ Once NSSI has been reported, the tone of questioning is particularly important. As many adolescents who self-injure are reticent to share and discuss their NSSI experiences because of stigma and concern about others' reactions, the initial response and tone of questions toward the youth is of particular importance and needs to convey an empathic tone and a sense of genuine curiosity about wanting to understand the patient's NSSI experience. .,62,63 $^{\text {, }}$

\section{Assessment}

A central purpose of assessment is to triage for level of risk in order to guide appropriate referral based on presence of high- riskindicators. The primary risk factors to assess are suicidality 
(C) This manuscript version is made available under the CC-BY-NC-ND 4.0 license https://creativecommons.org/licenses/by-nc-nd/4.0/

and medical severity of injury. ${ }^{4,5,64}$ Suicide assessment includes questions concerning past attempts, presence of suicidal ideation, intensity and frequency of ideation, as well as suicidal intent (ie, desire to die) and suicide plan. To evaluate a patient's plan, the physician would assess the plan's specificity including proposed suicide method, accessibility to method, lethality of method, and imminence of plan. ${ }^{64}$ Incidents of NSSI should also be evaluated for the medical severity of the injury. The greater degree of medical severity of the young patient's injuries contributes to a higher risk profile..$^{4,5,64}$

Furthermore, there are several factors known to be associated with a higher risk profile. These include multiple NSSI methods and/or locations of injuries and early age at onset. ${ }^{11}$ Similarly, a pattern of a longer history of NSSI and/or a recent worsening (eg, increased frequency and/or medical severity) of the behavior are both related to a higher risk profile. ${ }^{11}$ Also, if the patient reports self-injuring simultaneously with substance use, this is associated with a higher probability of more severe injury possibly because of impaired judgment, lowered inhibition, and/or pain dampening. ${ }^{62}$ In addition, a youth's perception that he/she is 'addicted to the selfinjury' is associated with more a severe profile of NSSI. ${ }^{21}$

Finally, inquiry regarding who the patient has told about his/her NSSI is essential in case management. In particular, it is important to know whether other professionals (eg, school counselor, psychologist) or adults (including family) or peers are aware of the behavior and their role in the patient's support network. One domain that is often overlooked is participation in online NSSI communities, which may reinforce the behavior. ${ }^{65-69}$

Youths' responses to the risk indicator assessment provide the physician with important details concerning the patient's NSSI to be shared at referral with the treatment provider. Evaluation of all risk indicators is important; however, high risk for suicide attempt and medical 
(C) This manuscript version is made available under the CC-BY-NC-ND 4.0 license

https://creativecommons.org/licenses/by-nc-nd/4.0/

severity of injury necessitate immediate referral. Identification of high-risk youth on other indicators noted above (other than suicide attempt and medical severity) suggests the need for prompt follow-up and ongoing monitoring.

\section{Recommendation for Referral and Management}

Patient referral for NSSI should include an awareness of cur- rent treatment recommendations for youth. Although there is a lack of empirically supported treatments for NSSI among youth, the existing evidence tentatively suggests that key elements in treatment should be drawn from a form of cognitive behavior therapy, dialectical behavior therapy. ${ }^{70-72}$ Specifically, treatment for adolescents who self-injure should begin with a functional assessment. ${ }^{70-72}$ which, involves the complex analysis of the antecedent events and consequences that may be contributing to the behavior. Antecedents and consequences include a variety of events (eg, relationshipdifficulties, failure), cognitions (eg, self-criticism, catastrophizing), and experienced emotion (eg, distress, self-hatred). Knowledge of the specific antecedents and consequences, in turn, will guide the focus of the treatment. From here, treatment consists of skills training in emotion regulation, distress tolerance, inter- personal skills, problem solving as well as cognitive restructuring. ${ }^{5,70-72}$ It is important to be cognizant that NSSI often co- occurs with other mental health difficulties (eg, depression, anxiety) and, thus, treatment planning may need to address these co-occurring issues. Inclusion of the family in treatment is highly

recommended. ${ }^{4,5,70-72}$ In light of the centrality of dialectical behavior therapy in treatment, referral should be made to a mental health professional familiar with this approach.

It is not uncommon for youth who engage in NSSI to be resistant to treatment and even refuse referral. If the assessment reveals a low level of risk, the physician will likely be in the position of having to manage the case. Case management in the event of refusal of treatment should include 
(C) This manuscript version is made available under the CC-BY-NC-ND 4.0 license https://creativecommons.org/licenses/by-nc-nd/4.0/

both the provision of resources, supports for the patient and family (eg, Self-injury Outreach and Support [www.sioutreach.org], The Cornell Research Program on Self-injury and Recovery [http://www. selfinjury.bctr.cornell.edu], and SAFE Alternatives [www.self- injury.com] all provide resources and recommended supports for a variety of stakeholders), as well as regularly scheduled follow-up appointments to evaluate for possible change, which would require hospitalization.

In light of the numerous risks associated with NSSI, in particular the risk for suicide, it is imperative that medical professionals receive current knowledge needed to effectively respond to young patients. With this information medical professionals are better equipped to respond effectively, thereby likely enhancing youth's openness to treatment for NSSI. 
(C) This manuscript version is made available under the CC-BY-NC-ND 4.0 license

https://creativecommons.org/licenses/by-nc-nd/4.0/

\section{References}

International Society for the Study of Self-injury. [homepage on the Internet]. http://www.isssweb.org.

Accessed July 15, 2013.

American Psychiatric Association. Diagnostic and statistical manual of mental disorders. 5th ed.

Arlington (VA): American Psychiatric Associ- ation; 2013.

Nock MK, Favazza AR. Nonsuicidal self-injury: definition and classifica- tion. In: Nock MK, ed.

Understanding nonsuicidal self-injury: origins, assessment and treatment. Washington (DC):

American Psychological Association; 2009. p. 9-18.

Klonsky ED, Muehlenkamp JJ, Lewis SP, Walsh B. Nonsuicidal self- injury. Cambridge (MA): Hogrefe Publishers; 2011.

Nixon MK, Heath NL, eds. Self-injury in youth: the essential guide to assessment and intervention. New York (NY): Routledge; 2008.

Jacobson CM, Gould M. The epidemiology and phenomenology of non- suicidal self-injurious behavior among adolescents: a critical review of the literature. Arch Suicide Res 2007;11:129-47.

Lewis SP, Heath NL. Five things to know about nonsuicidal self-injury. CMAJ 2013;185:505.

Lofthouse N, Muehlenkamp JJ, Adler R. Nonsuicidal self-injury and co- occurrence. In: Nixon MK, Heath NL, eds. Self-injury in youth: the essential guide to assessment and intervention. New York (NY): Rout- ledge; 2009. p. 59-78.

Nock MK. Self-injury. Annu Rev Clin Psychol 2010;6:339-63.

Klonsky ED, May AM, Glenn CR. The relationship between nonsuicidal self-injury and attempted suicide: converging evidence from four sam- ples. J Abnorm Psychol 2013;122:231-7.

Nock MK, Joiner TE, Gordon KH, Lloyd-Richardson E, Prinstein MJ. Nonsuicidal self-injury among adolescents: diagnostic correlates and relation to suicide attempts. Psychiatry Res 2006;144:65- 
(C) This manuscript version is made available under the CC-BY-NC-ND 4.0 license

https://creativecommons.org/licenses/by-nc-nd/4.0/

72.

Whitlock J, Muehlenkamp JJ, Eckenrode J, Purington A, Baral- Abrams G, Kress V. Nonsuicidal selfinjury as a gateway to suicide in ad- olescents and young adults. J Adolesc Health 2013;52:48692.

Duggan JM, Heath NL, Toste JR, Ross S. School counsellors' under- standing of nonsuicidal self-injury: experiences and international vari- ability. Can J Couns Psychother 2011;45:327-48.

Kerr PL, Muehlenkamp JJ, Turner JM. Nonsuicidal self-injury: a review of current research for family medicine and primary care physicians. J Am Board Fam Med 2010;23:240-59.

Taliaferro LA, Muehlenkamp JJ, Hetler J, Edwall G, Wright C, Edwards A, et al. Nonsuicidal self-injury among adolescents: a training priority for primary care providers. Suicide Life Threat Behav 2013;43: 250-61.

Jeffrey D, Warm A. A study of service providers' understanding of self- harm. J Ment Health 2002;11:295-303.

Rodham K, Hawton K. Epidemiology and phenomenology of nonsuici- dal self-injury. In: Nock MK, ed. Understanding nonsuicidal self-injury: origins, assessment and treatment. Washington (DC): American Psycho- logical Association; 2009. p. 37-62.

Ross S, Heath NL. A study of the frequency of self-mutilation in a com- munity sample of adolescents. J Youth Adolesc 2002;31:67-77.

Whitlock J, Eckenrode J, Silverman D. Self-injurious behaviors in a col- lege population. Pediatrics 2006;117:1939-48.

MacPhee SD, Toste JR, Heath NL. Risk factors for age of onset of non- suicidal self-injury. In: Proceedings of the annual International Society for the Study of Self-Injury; 2011. 2011 June; New York (NY). 
(C) This manuscript version is made available under the CC-BY-NC-ND 4.0 license

https://creativecommons.org/licenses/by-nc-nd/4.0/

Barrocas AL, Hankin BL, Young JF, Abela JR. Rates of nonsuicidal self- injury in youth: age, sex, and behavioral methods in a community sam- ple. Pediatrics 2012;130:39-45.

Muehlenkamp JJ, Gutierrez PM. An investigation of differences between self-injurious behavior and suicide attempts in a sample of adolescents. Suicide Life Threat Behav 2004;34:12-23.

Lloyd-Richardson EE, Perrine N, Dierker L, Kelley ML. Characteristics and functions of nonsuicidal self-injury in a community sample of ado- lescents. Psychol Med 2007;37:1183-92.

Laye-Gindhu A, Schonert-Reichl KA. Nonsuicidal self-harm among community adolescents: understanding the "whats" and "whys" of self-harm. J Youth Adolesc 2005;34:447-57.

Heath NL, Toste JR, Nedecheva T, Charlebois A. An examination of nonsuicidal self-injury among college students. J Ment Health Couns 2008;30:137-56.

Lewis SP, Arbuthnott AE. Nonsuicidal self-injury: characteristics, func- tions, and strategies. J College Stud Psychother 2012;26:185-200.

Sornberger MJ, Heath NL, Toste JR, McLouth R. Nonsuicidal self-injury and gender: patterns of prevalence, methods, and locations among ado- lescents. Suicide Life Threat Behav 2012;42:266-78.

Bjarrehed J, Lundh LG. Deliberate self-harm in 14-year-old adolescents: how frequent is it, and how is it associated with psychopathology, rela- tionship variables, and styles of emotional regulation. Cogn Behav Ther 2008;37:26-37.

Cerutti R, Manca M, Presaghi F, Gratz KL. Prevalence and clinical cor- relates of deliberate self-harm among a community sample of Italian ad- olescents. J Adolesc 2012;34:337-47.

Hankin BL, Abela JR. Nonsuicidal self-injury in adolescence: prospective rates and risk factors in a $2 \frac{1 / 2}{2}$ year longitudinal study. Psychiatry Res 2011;186:65-70.

Klonsky ED. The functions of deliberate self-injury: a review of the evi- dence. Clin Psychol Rev 
(C) This manuscript version is made available under the CC-BY-NC-ND 4.0 license

https://creativecommons.org/licenses/by-nc-nd/4.0/

2007;27:226-39.

Muehlenkamp JJ, Brausch AM. Body image as a mediator of nonsuicidal self-injury in adolescents. J

Adolesc 2012;35:1-9.

Ross S, Heath NL, Toste JR. Non-suicidal self-injury and eating pathol- ogy in high school students. Am J Orthopsychiatry 2009;79:83-92.

Hintikka J, Tolumen T, Rissanen ML, Honkalampi K, Kylm€ J, Laukkanen E. Mental disorders in self-cutting adolescents. J Adolesc Health 2009;44:464-7.

Peebles R, Wilson JL, Lock JD. Self-injury in adolescents with eating dis- orders: correlates and provider bias. J Adolesc Health 2011;48:310-3.

Jacobson CM, Muehlenkamp JJ, Miller AL, Turner JB. Psychiatric impairment among adolescents engaging in different types of deliberate self-harm. J Clin Child Adolesc Psychol 2008;37:36375.

Weierich MR, Nock MK. Posttraumatic stress symptoms mediate the relation between childhood sexual abuse and nonsuicidal self-injury. J Consult Clin Psychol 2008;76:39-44.

Wilkinson P, Kelvin R, Roberts C, Dubicka B, Goodyer I. Clinical and psychosocial predictors of suicide attempts and nonsuicidal self-injury in the adolescent depression antidepressants and psychotherapy trial (ADAPT). Am J Psychiatry 2011;168:495-501.

Muehlenkamp JJ, Ertelt TW, Miller AL, Claes L. Borderline personality symptoms differentiate nonsuicidal and suicidal self-injury in ethni- cally diverse adolescent outpatients. J Child Psychol Psychiatry $2011 ; 52: 148-55$.

Gratz KL, Conrad SD, Roemer L. Risk factors for deliberate self-harm among college students. Am J Orthopsychiatry 2002;72:128-40.

Yates TM. The developmental psychopathology of self-injurious behavior: compensatory regulation in 
(C) This manuscript version is made available under the CC-BY-NC-ND 4.0 license

https://creativecommons.org/licenses/by-nc-nd/4.0/

posttraumatic adaptation. Clin Psychol Rev 2004;24:35-74.

Klonsky ED, Moyer A. Childhood sexual abuse and nonsuicidal self- injury: meta-analysis. Br J

Psychiatry 2008;192:166-70.

Klonsky ED. The functions of self-injury in young adults who cut them- selves: clarifying the evidence for affect-regulation. Psychiatry Res 2008; 166:260-8.

Lewis SP, Santor DA. Development and validation of the self-harm rea- sons questionnaire. Suicide Life Threat Behav 2008;38:104-15.

Lewis SP, Santor DA. Self-harm reasons, goal achievement and predic- tion of future self-harm intent. J Nerv Ment Dis 2010;198:362-9.

Nock MK, Prinstein MJ. A functional approach to the assessment of self- mutilative behavior. J Consult Clin Psychol 2004;72:885-90.

Nock MK, Prinstein MJ. Contextual features and behavioral functions of self-mutilation among adolescents. J Abnorm Psychol 2004;114:140-6.

Nock MK, Mendes WB. Physiological arousal, distress tolerance and so- cial problem-solving deficits among adolescent self-injurers. J Consult Clin Psychol 2008;76:28-38.

Young R, Sweeting H, West P. Prevalence of deliberate self-harm and at- tempted suicide within contemporary goth youth subculture: longitudi- nal cohort study. BMJ 2006;332:1058-61.

Whitlock J, Muehlenkamp JJ, Purington A, Eckenrode J, Barreira J, Abrams GB, et al. Nonsuicidal selfinjury in a college population: general trends and sex differences. J Am Coll Health 2011;59:6918.

Sher L, Stanley BH. Biological model of nonsuicidal self injury. In: Nock MK, ed. Understanding nonsuicidal self-injury. Washington, DC: American Psychological Association; 2008. p. 99-117.

Stanley B, Sher L, Wilson S, Ekman R, Huang YY, Mann JJ. Nonsuicidal self-injurious behavior, 
(C) This manuscript version is made available under the CC-BY-NC-ND 4.0 license

https://creativecommons.org/licenses/by-nc-nd/4.0/

endogenous opioids and monoamine neuro- transmitters. J Affect Disord 2010;124:134-40.

Groschwitz RC, Plener PL. The neurobiology of nonsuicidal self-injury (NSSI): a review. Suicidol

Online 2012;3:24-42.

Crowell SE, Beauchaine TP, McCauley E, Smith CJ, Stevens AL, Sylvers P. Psychological, autonomic, and serotonergic correlates of para- suicide among adolescent girls. Dev Psychopathol 2005;17:1105-27.

Crowell SE, Beauchaine TP, McCauley E, Smith CJ, Vasilev CA, Stevens AL. Parent-child interactions, peripheral serotonin, and self- inflicted injury in adolescents. J Consult Clin Psychol 2008;76:1521.

Plener PL, Bubalo N, Fladung AK, Ludolph AG, Lulę D. Prone to excite- ment: adolescent females with nonsuicidal self-injury (NSSI) show altered cortical pattern to emotional and NSS-related material. Pscyhia- try Res 2012;203:146-52.

Plener PL, Libal G, Nixon MK. Use of medication in the treatment of nonsuicidal self-injury in youth. In: Nixon MK, Heath NL, eds. Self- injury in youth: the essential guide to assessment and intervention. New York (NY): Routledge; 2009. p. 275-308.

Muehlenkamp JJ, Gutierrez PM. Risk for suicide attempts among ado- lescents who engage in nonsuicidal self-injury. Arch Suicide Res 2007; 11:69-82.

Glenn CR, Klonsky ED. Social context during nonsuicidal self-injury in- dicates suicide risk. Pers Individ Dif 2009;46:25-9.

Muehlenkamp JJ. Self-injurious behavior as a separate clinical syn- drome. Am J Orthopsychiatry 2005;75:324-33.

Guan K, Fox KR, Prinstein MJ. Nonsuicidal self-injury as a time- invariant predictor of adolescent suicide ideation and attempts in a diverse community sample. J Consult Clin Psychol 
(C) This manuscript version is made available under the CC-BY-NC-ND 4.0 license https://creativecommons.org/licenses/by-nc-nd/4.0/

2012;80:842-9.

Klonsky ED, Lewis SP. Assessment of nonsuicidal self-injury. In: Nock MK, ed. Oxford handbook of suicide and self-injury. New York (NY): Oxford University Press; 2014. p. 337-54.

Walsh BW. Treating self-injury: A practical guide. 2nd ed. New York (NY): Guilford Press; 2012.

Shea SC. The practical art of suicide assessment: A guide for mental health professionals and substance abuse counselors. Hoboken (NJ): John Wiley and Sons Inc; 1999.

Lewis SP, Baker TG. The possible risks of self-injury websites: a content analysis. Arch Suicide Res 2012;15:390-6.

Lewis SP, Heath NL, St Denis JM, Noble R. The scope of nonsuicidal self- injury on YouTube. Pediatrics 2011;127:e552-8.

Lewis SP, Rosenrot SR, Messner MN. Seeking validation in unlikely pla- ces: what people ask about nonsuicidal self-injury online. Arch Suicide Res 2012;16:263-72.

Lewis SP, Heath NL, Michal N, Duggan JM. Nonsuicidal self-injury, youth and the Internet: what mental health professionals need to know. Child Adolesc Psychiatry Ment Health 2012;6:13.

Lewis SP, Heath NL, Sornberger MJ, Arbuthnott AE. Helpful or harm- ful? An examination of viewers' responses to nonsuicidal self-injury videos on YouTube. J Adolesc Health 2012;51:280-5.

Hollander M. Helping teens who cut: Understanding and ending self- injury. New York (NY): Guilford Press; 2008.

Washburn JJ, Richardt SL, Styer DM, Gebhardt M, Juzwin KR, Yourek A, et al. Psychotherapeutic approaches to nonsuicidal self- injury in adolescents. Child Adolesc Psychiatry Ment Health 2012;6:14.

Vale H, Nixon MK, Kucharski A. Working with families and adolescents with NSSI. In: Nixon MK, Heath NL, eds. Self-injury in youth: the essential guide to assessment and intervention. New York (NY): 
(C) This manuscript version is made available under the CC-BY-NC-ND 4.0 license https://creativecommons.org/licenses/by-nc-nd/4.0/

Routledge; 2009. 
(C) This manuscript version is made available under the CC-BY-NC-ND 4.0 license https://creativecommons.org/licenses/by-nc-nd/4.0/

\section{Tables and Figures}

Table. Sample questions for gathering information about NSSI from patient

Questions would typically assess for NSSI in the following sequence

1. Overallhowstressedhastheyouth beenfeelingoverthepastfewweek? Month?

a. Probe: asking youth to speak of his/her stress

2. Overallhowhas theyouth's mood beenduring this period?

a. Probe: Depressive symptoms? Anxiety? Combination?

3. At this point introduce the ideathatyouth who are struggling with stress, mood, oranxietyissuessometimesengageinbehaviorssuchas substance misuse or other self-harming behaviors (ie, self-injury).

4. Ask the youth if he/she has tried these strategies to cope with stress or emotions.

5. If youth reports engaging in self-injury then assess on following factors.

a. Immediately clarify the nonsuicidal nature of the behavior and possible co-occurring suicidal behaviors

b. Determine onset and NSSI history

c. Assess the current frequency, methods, and medical severity of NSSI

d. Ask about simultaneous substance use

e. Inquire about perceived addictive features of the NSSI

f. Askwhohe/shehastoldabouttheirNSSI (including onlineactivity) 